\title{
Health-related quality of life, handgrip strength and falls during detraining in elderly habitual exercisers
}

\author{
Izaro Esain, Ana Rodriguez-Larrad, Iraia Bidaurrazaga-Letona and Susana María Gil
}

\begin{abstract}
Background: The effects of regular exercise on physical functioning and health-related quality of life (HRQOL) have been thoroughly studied. In contrast, little is known about the changes which occur following cessation of activity (detraining). Here, we have investigated the effect of a 3 month detraining period on HRQOL and on handgrip strength in elderly people who had regularly exercised, and examined the association of these variables with falls.

Methods: Thirty-eight women and 11 men (mean age, 75.5 \pm 5.7 years) took part in a supervised physical exercise program for 9 months, followed by a 3 month detraining period. Participants completed the SF-36 HRQOL questionnaire at the beginning of detraining (baseline) and 3 months later. Handgrip strength and number of falls were also recorded.

Results: Participants had been exercising for $12.1 \pm 8.7$ years. After the detraining period, we found a significant $(p<0.001-0.05)$ decline in all SF-36 dimensions, with the exception of handgrip strength. Women presented a larger decline $(p<0.05)$ in more items than men. During the detraining period, $18.4 \%$ participants had a fall incident. HRQOL declined in both fallers and non-fallers during detraining. Interestingly, fallers already had at baseline significantly lower values in physical functioning $(p<0.05)$, emotional role $(p<0.05)$ and mental health $(p<0.01)$, than non-fallers.

Conclusions: An important decline was found in most items of the SF-36 following a 3 month detraining period, particularly in women. In contrast, strength of the upper limb was not affected by the detraining. The prior lower HRQOL values of those who will subsequently fall suggest that this criterion should be studied as a candidate risk factor for falls. Efforts should be made to encourage the elderly to continue with exercise activities and/or to shorten holiday break periods, in order to maintain their quality of life.
\end{abstract}

Trial registration: The protocol was registered as a clinical trial in the ANZCTR (trial ID: ACTRN12617000716369).

Keywords: Quality of life, Elderly, Supervised physical activity, Fall

\section{Background}

In recent years, the proportion of older people is increasing all over the world. According to the latest data from the World Health Organization (WHO), between 2015 and 2050 the proportion of older people will increase from 12 to $22 \%$, which means an increase from 900 million to 2 billion elderly people 60 years old [1]. Aging is considered a deleterious, progressive, intrinsic and universal process which occurs in every living being over time as an expression of the interaction between the individual's genetic program and

\footnotetext{
* Correspondence: susana.gil@ehu.eus

Department of Physiology, Faculty of Medicine and Nursing, University of the Basque Country (UPV/EHU), Barrio Sarriena s/n, E-48940 Leioa, Bizkaia, Spain
}

its environment [2]. One of the implications of aging is that falls and fall-related injuries are common in older populations. In fact, about one-third of people over the age of 65 fall at least once a year [3]. These falls are a cause of high mortality and morbidity and have negative effects on quality of life and independence [4].

It has been demonstrated that physical activity is an important factor to achieve healthy aging [5]. According to May et al., physical activity provides a longer life in good health [6], and physical training reduces the effects of aging on functional fitness [7]. Among other factors, falls in elderly people are related to low levels of muscular strength [8] and impaired balance [9]; thus, physical 
activity constitutes and optimal preventive strategy and plays an important role in the prevention of falls [10].

Handgrip strength is an indicator of general muscle strength and it is associated with fragility and propensity to fall [11]. Moreover, the decline in handgrip strength is related to the loss of physical functionality [12]. In a systematic review Bohannon concluded that grip strength should be considered as a useful measure for the screening of the health condition of elderly individual [13]. The utilization of grip strength is supported because of its predictive validity, measurement properties, simplicity, portability and affordability [13].

According to the WHO, quality of life is defined as the individual's perception of their position in life, in the cultural context, in the value system in which they live and in relation to their goals, expectations, norms and concerns. This concept also encompasses physical health, psychological status, level of independence, social relationships, environmental factors and also personal beliefs [14]. In order to quantify health-related quality of life, the SF-36 health questionnaire has been widely used, being one of the most employed instruments [15, 16], particularly for elderly people [17-19]. The functional autonomy of the elderly affects their quality of life, with exercise being a protector and precursor of this autonomy [20]. Therefore, the promotion of active aging with more years free from functional limitations, coupled with compensatory strategies supporting autonomy and independence among older adults, are fundamental for their quality of life and happiness [21].

While the beneficial effects of regular physical exercise (training) on physical functioning and quality of life have been widely reported in the literature [22, 23], less attention has been given to changes occurring following cessation of activity [24], i.e. detraining. Most published studies in this regard have analyzed the effect of detraining on muscle function and physical performance [24, 25]. In this sense, it has been observed that following a 9 week multicomponent exercise training program in which elderly subjects improved in strength, agility, flexibility and balance, 6 weeks of detraining was found to induce a significant decline in functional fitness [25]. Similarly, Bocalini et al. observed that functional fitness improved in women older than 62 years who took part in water-based exercises for 12 weeks, three times per week; however, after 6 weeks of detraining they displayed a substantial decline in all the functional fitness tests [26].

Surprisingly, little data is available regarding the influence of detraining on quality of life. In this regard, questionnaires such as the Nottingham Health profile [27], the University of Queensland Quality of Life Questionnaire [24] and WHO quality of life questionnaires [26], have been used, but to the best of our knowledge, only one study has analyzed the effect of the cessation of exercise on the SF-36 in healthy participants [28]. In that study, the authors observed that after a year of training followed by 3 months of detraining, agility/dynamic balance, lower body strength and flexibility were the components most affected, while the HRQOL remained unchanged [28]. Nevertheless, in the mentioned study quality of life was displayed as a unique score; consequently, a more profound analysis of the effects of detraining on the different items of the SF36 would be worthwhile.

The majority of studies in this area have investigated the effect of detraining after a period of training in previously sedentary people. Thus, little is known about the effect of detraining on habitual exercisers. The availability of the older adult to take extended holidays, coupled with volunteering or family commitments [24], and the interruption of exercise classes due to summer vacations may lead to periods of training cessation. In these situations, it is not uncommon that people accustomed to regular exercise, particularly the elder, complain about stiffness of the joints, increased body pain and a decline in their well-being. Taking into account the benefits of physical activity on the quality of life of the elderly, it would be interesting to ascertain to what extent quality of life changes during the detraining period in habitual elderly exercisers. Moreover, it is of interest to study if a period of detraining impairs strength. Thus, it would be interesting to understand if there is a link between detraining and the number of falls in the elderly, and its relationship with quality of life and strength. Thus, we aimed to evaluate the hypothesis that a period of exercise cessation in habitual exercisers would deteriorate their quality of life, particularly in terms of the items related to physical function. Also, due to the fact that detraining produces a decline in physical function, it could be expected that the number of falls would increase in elderly people accustomed to regular exercise, and that this would consequently affect their quality of life.

The purpose of the present study was to evaluate the effect of 3 months of detraining on elderly men and women, who had previously practiced regular supervised physical activity, in terms of quality of life and handgrip strength and also its relationships with falls.

\section{Methods}

\section{Study design and recruitment}

Participants were recruited from a supervised physical exercise program offered to people aged over 65 years in a public sports center in Getxo (Bizkaia, Basque Country). The inclusion criteria were to be enrolled in a supervised group exercise program for people aged over 65 during the previous 9 months, at least. All potential participants received detailed study information in their sports center through the research team. Sixty-eight older adults met the inclusion criteria and were contacted for eligibility; 
nine of them declined to participate, therefore 57 participants were recruited for the study and completed the baseline assessment. For different reasons eight people left the study so at the end we analysed 49 subjects. Objectives, measurement variables and other details were also explained orally. Informed consent was obtained from each participant who signed it after fully understanding the procedures. The study was approved by the Ethics Committee of the University of the Basque Country (UPV/EHU) (M10_2015-204). The protocol was registered as a clinical trial in the Australian New Zealand Clinical Trials Protocol (trial ID: ACTRN12617000716369).

The participants were attending two group sessions/week multicomponent program. Each session lasted $50 \mathrm{~min}$. The session consisted of a $15 \mathrm{~min}$ warm-up to prepare for the session. This consisted of performing joint movements while listening to music; subsequently, they played a simple racquet game using a soft ball. During the main part of the session, they performed strength exercises of major muscle groups, static and dynamic balance exercises, and reaction speed exercises, finishing with stretching. All sessions were guided by the same experienced professional throughout the training period. The program had a length of 9 months and had a scheduled cessation period of 3 months during the summer, for summer holidays. The detraining period was arranged to coincide with this annual break. During detraining, participants were asked to maintain their normal activities of daily living, and to abstain from participating in supervised exercise programs. All the participants were scheduled to stop the exercise program. They were aware of this situation at the beginning of the study.

\section{Study measures}

Measurements were performed twice: First, at the end of the 3 month exercise program, i.e. before discontinuing the program due to the summer period (detraining period), in June. These measurements were considered the baseline measurements. Second, measurements were undertaken again 3 months later, after the 3 months of the detraining period, in September.

The primary outcome measure was the difference in quality of life at the end of the detraining period assessed by scoring each dimension of the HRQOL. This was measured using the 36-item short form survey (SF-36), which is a generic questionnaire whose translation into Spanish has been validated [16]. It is designed to measure the selfreporting health status of the individual. The 36 items are grouped into 8 different dimensions: physical functioning, physical role functioning, bodily pain, general health, vitality, social role functioning, emotional role functioning and mental health. Each subscale score was transformed according to the manual from 0 to 100 , with 0 being the worst and 100 the best.
The second outcome was the number of falls during the detraining period, which is defined as an unexpected event in which the participant comes to rest on the ground, floor or lower level [29]. To measure this, participants were asked about any falls which had occurred during the detraining period. Age, gender and anthropometric data were also recorded. Weight and height were measured using Seca (Model 869) instruments; from this, the body mass index was calculated (BMI, $\mathrm{kg} / \mathrm{m}^{2}$ ). The circumference of the waist and hip was measured and the waist-hip ratio calculated. All measurements were preformed following the standards of the International Society for the Advancement of Kinanthropometry [30].

Grip strength has been recommended as an assessment technique for the measurement of muscle strength and muscle function in clinical practice [31]. Moreover, lower values of grip strength have been related to an increased number of falls in adults [32]. Therefore, grip strength of the dominant hand was measured using a Jamar Plus digital hand dynamometer. Subjects were seated with back, pelvis, and knees as close to 90 degrees as possible, shoulder adducted and neutrally rotated, elbow flexed at 90 degrees, forearm neutral and wrist held between 0 and 15 degrees of ulnar deviation. The arm was not supported by examiner or armrest and the dynamometer was presented vertically and in line with the forearm [33]. The participants were given verbal encouragement to achieve maximal strength. The mean of three trials was recorded.

\section{Statistical analysis}

Sample size was calculated to detect minimal significant effects on the variable of handgrip strength, accepting a two-sided significance level of 0.05 , a clinically relevant improvement of $2 \mathrm{~kg}$ in handgrip strength and a standard deviation of $3 \mathrm{~kg}$, and a power of $90 \%, 47$ individuals are required. Presuming a drop-out of $5 \%$, the resultant sample size was determined in 50 individuals.

Data was analyzed using Statistical Package for Social Sciences IBM software (SPSS version 21.0). Normality of data was assessed using the Kolmogorov-Smirnov test. Mean and standard deviations were used as descriptive statistics. To identify significant differences (with respect to baseline) in all variables after the 3 months of detraining (3 month), a Wilcoxon test for dependent samples was used. Also the change of each variable was calculated as a percentage using the following formula: ( 3 month - baseline)/baseline* 100 .

We used Mann-Whitney U statistics for 2 group comparisons. To compare the results of the present study to data of the general population [34] the effect size was used, evaluating Cohen's d parameter. Threshold values for effect size statistics were $0.2,0.5$ and 0.8 for small, medium and large effect sizes, respectively [35]. Mean 
differences between baseline and 3 months were calculated, as well as $95 \%$ confidence intervals. In all cases, the level of significance was set at $p<0.05$.

\section{Results}

As can be observed in Table 1, no significant changes were observed in the anthropometric measurements after the detraining period.

Regarding the HRQOL, statistically significant $(p<0.05-$ $p<0.001)$ differences were observed in all the items after the detraining period; see Table 2.

When we analyzed the HRQOL taking into account the sex of the participants, there were no statistically significant differences between men and women. However, at baseline, men displayed higher values than women in all items. The exception was social functioning in which women displayed slightly higher values than men $(95.0 \pm 9.5$ vs. $93.1 \pm 8.5)$ (Table 3).

After the detraining period, both women and men displayed statistically lower values $(p<0.05-p<0.001)$ in the dimensions of physical functioning, bodily pain, emotional role functioning and mental health. Additionally, women had lower values in the dimensions of vitality $(\mathrm{p}<0.001)$ and social functioning $(p<0.01)$.

During the three-month period of study, 9 (18\%) falls were reported. Of these, 8 (89\%) were women and 1 (11\%) men. At baseline, participants who afterwards had a fall, displayed statistically lower values in physical functioning $(p<0.05)$, emotional role functioning $(p<0.05)$ and mental health $(p<0.01)$ than the non-fallers. Moreover, after the detraining period, fallers had lower values in physical role functioning $(p<0.05)$, general health $(p<0.05)$ and mental health $(p<0.05)$ (Table 4).

When we compared the values at baseline and after 3 months, we observed that both fallers and non-fallers had lower values in all dimensions after the detraining period. In the non-fallers group, we observed statistically

Table 1 Characteristics of the study sample

\begin{tabular}{lcc}
\hline & $\begin{array}{l}\text { Baseline } \\
\mathrm{m} \pm \mathrm{sd}\end{array}$ & $\begin{array}{c}3 \text { months } \\
\mathrm{m} \pm \mathrm{sd}\end{array}$ \\
\hline Age (years old) & $75.55 \pm 5.77$ & - \\
Female & $38(77.6 \%)$ & - \\
Male & $11(22.4 \%)$ & - \\
Height (cm) & $159.80 \pm 7.34$ & $159.81 \pm 7.34$ \\
Weight (kg) & $72.63 \pm 12.98$ & $72.63 \pm 13.02$ \\
BMl & $28.41 \pm 4.58$ & $28.40 \pm 4.56$ \\
Waist-Hip ratio & $0.90 \pm 0.06$ & $0.92 \pm 0.06$ \\
Years of physical activity & $12.10 \pm 8.80$ & - \\
Non-fallers (number) & - & $40(81.6 \%)$ \\
Fallers (number) & - & $9(18.4 \%)$ \\
\hline Abbreviations: BMI body &
\end{tabular}

Abbreviations: $B M I$ body mass index, $M$ mean, $S D$ standard deviation significant lower values in the dimensions of physical functioning $(p<0.001)$, bodily pain $(p<0.01)$, vitality $(p<0.01)$, emotional role functioning $(p<0.05)$ and mental health $(p<0.001)$. In contrast, in the group that suffered a fall, statistically significant differences $(p<0.05)$ were found in the dimensions of physical functioning, bodily pain, vitality and social role functioning.

Regarding the handgrip strength, men displayed larger values than women $(p<0.001)$ (Table 3$)$. No changes were observed along the detraining period (Table 2). In addition, handgrip strength was similar in fallers and non-fallers both at the beginning and the end of the study (Table 4).

\section{Discussion}

The benefits of exercise and physical activity on the different aspects of health, including quality of life, have been widely investigated; however, little is known about the impact of the cessation of supervised physical exercise on the quality of life of healthy elderly people who exercise regularly. Taking into account that supervised exercise programs may have predicted (summer holidays) or unpredicted (illnesses or family care) cessation periods, the aim of the present study was to ascertain the effect of a detraining period on the quality of life and handgrip strength, and the relation to falls in elderly exercisers. An important decline was found in most items of the SF-36 following a 3 month detraining period, particularly in women and in those participants who had a fall. Moreover, fallers already had at baseline significantly lower values in several items related to the quality of life prior to the fall incident.

It is well recognized that physical activity is positively related to the quality of life of elderly people $[23,36]$. This notion, coincides with the fact that participants of the present study, who had been attending exercise classes for an average of 12 years, displayed larger values in most items of the quality of life than people of the general population [34] reinforcing the positive effect of physical exercise on the quality of life of the aging adults.

Interestingly, this better quality of life of the habitual exercisers of the present study suffered an important decline only after 3 months of exercise cessation. Only a few studies have analyzed the effect of detraining on quality of life, delivering conflicting results. While some authors did not observe any changes in quality of life after a 3 month detraining period [28, 37], Bocalini et al. observed a significant decrement at 4 weeks and a larger one at 6 weeks, comparable to the present results [26]. The cessation of physical exercise has been associated with reduced aerobic capacity, body strength, agility, flexibility and static balance [26] which may explain the decline in the items related with physical function (physical functioning, role physical, bodily pain and general health). 
Table 2 Health-related quality of life (HRQOL) and handgrip strength of participants before (baseline) and after (3 months) detraining

\begin{tabular}{|c|c|c|c|c|c|}
\hline & Baseline $\mathrm{m} \pm \mathrm{sd}$ & 3 months $\mathrm{m} \pm \mathrm{sd}$ & $d$ & Mean difference $(95 \% \mathrm{Cl})$ & $p$-value \\
\hline HRQOL (SF-36) Physical func. & $91.4 \pm 8.9$ & $84.1 \pm 11.9$ & -0.61 & $-7.3(-9.5-(-) 5.2)$ & $<0.001$ \\
\hline Physical role func. & $96.4 \pm 12.5$ & $87.8 \pm 28.9$ & -0.29 & $-8.7(-17.7-0.3)$ & 0.05 \\
\hline Bodily pain & $80.8 \pm 19.9$ & $66.0 \pm 22.1$ & -0.66 & $-14.7(-20.6-(-) 8.8)$ & $<0.001$ \\
\hline General health & $71.6 \pm 17.8$ & $67.6 \pm 17.1$ & -0.23 & $-3.9(-7.7-(-) 0.2)$ & 0.02 \\
\hline Vitality & $77.4 \pm 15.4$ & $69.2 \pm 15.1$ & -0.54 & $-8.2(-11.7-(-) 4.7)$ & $<0.001$ \\
\hline Social role func. & $94.6 \pm 9.5$ & $85.9 \pm 18.2$ & -0.48 & $-8.8(-13.8-(-) 3.7)$ & 0.001 \\
\hline Emotional role func. & $91.2 \pm 25.3$ & $77.5 \pm 36.9$ & -0.37 & $-13.7(-23.3-(-) 4.1)$ & 0.004 \\
\hline Mental health & $77.7 \pm 17.5$ & $71.4 \pm 16.2$ & -0.39 & $-6.4(-10.8-(-) 1.9)$ & $<0.001$ \\
\hline \multicolumn{6}{|l|}{ STRENGTH } \\
\hline Handgrip strength (kg) & $25.2 \pm 6.4$ & $25.3 \pm 6.4$ & 0.01 & $0.12(-0.63-0.84)$ & $>0.05$ \\
\hline
\end{tabular}

Abbreviations: Func. functioning, HRQOL health related quality of life, $C l$ confidence interval, $m$ mean, $s d$ standard deviation, $d$ Cohen's $d$

Table 3 Health-related quality of life (SF-36) and handgrip strength of participants before (Baseline) and after (3 months) the detraining period, by sex

\begin{tabular}{|c|c|c|c|}
\hline & & Female (m $\pm s d)$ & 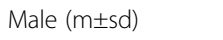 \\
\hline \multirow[t]{2}{*}{ HRQOL (SF-36) Physical func. } & Baseline & $90.2 \pm 9.6$ & $95.4 \pm 3.5$ \\
\hline & 3 months & $83.0 \pm 12.6^{* * *}$ & $87.7 \pm 9.04^{*}$ \\
\hline Mean difference $(95 \% \mathrm{Cl})$ & & $-7.2(-9.7-(-) 4.7)$ & $-7.7(-13.2-(-) 2.2)$ \\
\hline \multirow[t]{2}{*}{ Physical role func. } & Baseline & $96.0 \pm 12.6$ & $97.7 \pm 7.5$ \\
\hline & 3 months & $88.1 \pm 28.3$ & $86.3 \pm 32.3$ \\
\hline Mean difference $(95 \% \mathrm{Cl})$ & & $-7.8(-18.0-2.2)$ & $-11.3(-34.3-11.6)$ \\
\hline \multirow[t]{2}{*}{ Bodily pain } & Baseline & $79.3 \pm 20.4$ & $85.5 \pm 17.7$ \\
\hline & 3 months & $64.4 \pm 23.0^{* * *}$ & $71.4 \pm 18.3^{*}$ \\
\hline Mean difference $(95 \% \mathrm{Cl})$ & & $-14.8(-21.9-(-) 7.8)$ & $-14.0(-26.1-(-) 2.0)$ \\
\hline \multirow[t]{2}{*}{ General health } & Baseline & $70.0 \pm 18.8$ & $76.9 \pm 12.6$ \\
\hline & 3 months & $67.3 \pm 18.25$ & $68.2 \pm 13.2$ \\
\hline Mean difference $(95 \% \mathrm{Cl})$ & & $-2.6(-6.4-1.2)$ & $-8.6(-20.0-2.7)$ \\
\hline \multirow[t]{2}{*}{ Vitality } & Baseline & $77.3 \pm 16.2$ & $77.2 \pm 12.5$ \\
\hline & 3 months & $68.9 \pm 16.4^{* * *}$ & $70.0 \pm 10.0$ \\
\hline Mean difference $(95 \% \mathrm{Cl})$ & & $-8.4(-12.4-(-) 4.4)$ & $-7.2(-15.8-1.2)$ \\
\hline \multirow[t]{2}{*}{ Social role func. } & Baseline & $95.0 \pm 9.8$ & $93.1 \pm 8.5$ \\
\hline & 3 months & $87.0 \pm 18.2^{* *}$ & $81.6 \pm 17.9$ \\
\hline Mean difference $(95 \% \mathrm{Cl})$ & & $-7.9(-13.5-(-) 2.4)$ & $-11.5(-25.2-2.1)$ \\
\hline \multirow[t]{2}{*}{ Emotional role func. } & Baseline & $89.4 \pm 28.0$ & $96.9 \pm 10.0$ \\
\hline & 3 months & $79.7 \pm 36.8^{*}$ & $69.5 \pm 37.9^{*}$ \\
\hline Mean difference $(95 \% \mathrm{Cl})$ & & $-9.7(-20.4-1.0)$ & $-27.4(-49.5-(-) 5.3)$ \\
\hline \multirow[t]{2}{*}{ Mental health } & Baseline & $76.0 \pm 18.3$ & $83.6 \pm 12.9$ \\
\hline & 3 months & $71.0 \pm 17.2^{* *}$ & $72.3 \pm 12.5^{*}$ \\
\hline Mean difference $(95 \% \mathrm{Cl})$ & & $-4.9(-10.2-0.3)$ & $-11.2(-19.4-(-) 3.05)$ \\
\hline \multicolumn{4}{|l|}{ STRENGTH } \\
\hline \multirow[t]{2}{*}{ Handgrip strength (kg) } & Baseline & $22.6 \pm 3.6$ & $34.3 \pm 6.1^{\text {ffキ }}$ \\
\hline & 3 months & $22.8 \pm 3.5$ & $34.1 \pm 7.1^{\neq \neq \ddagger}$ \\
\hline Mean difference $(95 \% \mathrm{Cl})$ & & $0.2(-0.5-0.9)$ & $-0.2(-2.9-2.5)$ \\
\hline
\end{tabular}

Abbreviations: $H R Q O L$ health related quality of life, $\mathrm{Cl}$ confidence interval, Func. functioning

Notes: $\mathrm{p}<0.05,{ }^{* *} \mathrm{p}<0.01,{ }^{* * *} \mathrm{p}<0.001$, statistically significant differences, baseline vs. 3 months

${ }^{\neq \neq \ddagger} p<0.001$, statistically significant differences female vs. male 
Table 4 Health-related quality of life (SF-36) and handgrip strength before (Baseline) and after (3 months) the detraining period in fallers and non-fallers

\begin{tabular}{|c|c|c|c|}
\hline & & 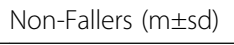 & 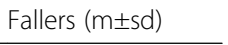 \\
\hline \multirow[t]{2}{*}{ HRQOL (SF-36) Physical func. } & Baseline & $91.6 \pm 9.4$ & $90.5 \pm 5.8^{\ddagger}$ \\
\hline & 3 months & $84.7 \pm 12.7^{* * *}$ & $81.1 \pm 7.8^{*}$ \\
\hline Mean difference $(95 \% \mathrm{Cl})$ & & $-6.8(-9.4-(-) 4.3)$ & $-9.4(-13.9-(-) 4.9)$ \\
\hline Mean change (\%) & & $-7.6 \pm 9.0$ & $-10.4 \pm 6.4$ \\
\hline \multirow[t]{2}{*}{ Physical role func. } & Baseline & $96.2 \pm 13.3$ & $97.2 \pm 8.3$ \\
\hline & 3 months & $92.5 \pm 22.0$ & $66.6 \pm 45.0^{\ddagger}$ \\
\hline Mean difference $(95 \% \mathrm{Cl})$ & & $-3.7(-12.3-4.8)$ & $-30.5(-62.0-0.9)$ \\
\hline Mean change (\%) & & $-2.5 \pm 54.1$ & $-33.3 \pm 45.0$ \\
\hline \multirow[t]{2}{*}{ Bodily pain } & Baseline & $81.1 \pm 19.9$ & $78.8 \pm 20.7$ \\
\hline & 3 months & $68.3 \pm 20.7^{* *}$ & $56.0 \pm 26.1^{*}$ \\
\hline Mean difference $(95 \% \mathrm{Cl})$ & & $-12.8(-19.5-(-) 6.1)$ & $-22.8(-35.9-(-) 9.8)$ \\
\hline Mean change (\%) & & $-13.4 \pm 25.3$ & $-30.4 \pm 25.6$ \\
\hline \multirow[t]{2}{*}{ General health } & Baseline & $73.9 \pm 16.9$ & $60.7 \pm 18.5$ \\
\hline & 3 months & $70.6 \pm 15.3$ & $54.2 \pm 19.1^{\ddagger}$ \\
\hline Mean difference $(95 \% \mathrm{Cl})$ & & $-3.3(-7.4-0.7)$ & $-6.5(-17.6-4.5)$ \\
\hline Mean change (\%) & & $-1.7 \pm 21.4$ & $-9.1 \pm 22.8$ \\
\hline \multirow[t]{2}{*}{ Vitality } & Baseline & $78.6 \pm 13.0$ & $71.6 \pm 23.3$ \\
\hline & 3 months & $71.5 \pm 12.5^{* *}$ & $58.8 \pm 21.4^{*}$ \\
\hline Mean difference $(95 \% \mathrm{Cl})$ & & $-7.1(-11.1-(-) 3.1)$ & $-12.7(-19.9-(-) 5.5)$ \\
\hline Mean change (\%) & & $-7.4 \pm 16.9$ & $-19.8 \pm 15.8$ \\
\hline \multirow[t]{2}{*}{ Social role func. } & Baseline & $95.6 \pm 8.27$ & $90.2 \pm 13.6$ \\
\hline & 3 months & $88.6 \pm 15.7^{* *}$ & $73.5 \pm 23.7^{*}$ \\
\hline Mean difference $(95 \% \mathrm{Cl})$ & & $-7.0(-12.5-(-) 1.4)$ & $-16.7(-30.3-(-) 3.1)$ \\
\hline Mean change (\%) & & $-6.6 \pm 18.3$ & $-19.2 \pm 18.9$ \\
\hline \multirow[t]{2}{*}{ Emotional role func. } & Baseline & $94.1 \pm 21.2$ & $77.7 \pm 37.7^{\ddagger}$ \\
\hline & 3 months & $82.4 \pm 31.2^{*}$ & $55.5 \pm 52.7$ \\
\hline Mean difference $(95 \% \mathrm{Cl})$ & & $-11.7(-22.1-(-) 1.3)$ & $-22.2(-50.8-6.4)$ \\
\hline Mean change (\%) & & $-9.5 \pm 45.3$ & $-37.5 \pm 51.7$ \\
\hline \multirow[t]{2}{*}{ Mental health } & Baseline & $80.9 \pm 16.1$ & 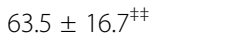 \\
\hline & 3 months & $73.9 \pm 15.4^{* * *}$ & $60.0 \pm 15.4^{\ddagger}$ \\
\hline Mean difference $(95 \% \mathrm{Cl})$ & & $-7.0(-12.3-(-) 1.7)$ & $-3.5(-10.8-3.7)$ \\
\hline Mean change (\%) & & $-2.9 \pm 48.6$ & $-4.6 \pm 14.3$ \\
\hline \multicolumn{4}{|l|}{ STRENGTH } \\
\hline \multirow[t]{2}{*}{ Handgrip (kg) } & Baseline & $25.2 \pm 7.0$ & $25.3 \pm 3.6$ \\
\hline & 3 months & $25.4 \pm 7.1$ & $25.0 \pm 2.5$ \\
\hline Mean difference $(95 \% \mathrm{Cl})$ & & $0.2(-0.7-1.1)$ & $-0.3(-1.9-1.3)$ \\
\hline Mean change (\%) & & $1.3 \pm 10.0$ & $-0.5 \pm 7.7$ \\
\hline
\end{tabular}

Abbreviations: $H R Q O L$ health-related quality of life, $\mathrm{Cl}$ confidence interval, Func. functioning Notes: $p<0.05,{ }^{* *} p<0.01,{ }^{* * *} p<0.001$, statistically significant differences baseline vs. 3 months ${ }^{\ddagger} \mathrm{p}<0.05,{ }^{\neq \neq} \mathrm{p}<0.01$, statistically significant differences non-fallers vs. fallers

Moreover, since participants in the present study had been exercising in groups for a long time, it is possible that those who lived alone or who looked after a husband/spouse or other family member during the summer break would, as a consequence of detraining, have had fewer opportunities for socialization and breaking their routines, thereby leading to a decline in the psycho- and social related items of the quality of life. 
It has previously been demonstrated that women in the general population have a lower quality of life than men $[38,39]$. Although not statistically significant, the women in the present study also reported lower values in most items of the HRQOL compared to men, at baseline. Nevertheless, it is remarkable that the effect of detraining was larger in women than in men. In fact, whereas both men and women experienced a decline in physical functioning, bodily pain, emotional role functioning and mental health, women declined additionally in vitality and social role functioning. Consequently, in order to maintain their quality of life it is advisable to encourage people who attend guided exercise programs, to engage in some kind of group exercise or other type of gathering in order to maintain their well-being during long periods of cessation of physical activity. This advice should particularly be delivered to women exercisers.

During the 3 month detraining period, $18.4 \%$ of participants suffered a fall, which is higher than what could be expected [40]. Toulette et al. observed that the beneficial effects of training significantly dropped in both fallers and non-fallers during 3 months of detraining, particularly in terms of walking parameters (walking speed, cadence and stride length) and of balance [41]. We could not observe any changes in the handgrip strength during the detraining and there were not differences between fallers and non-fallers. Nonetheless, it is likely that detraining leads to deterioration in strength of the lower limb, coordination and balance, increasing the risk of falls, which should be counterbalanced by different activities in the periods of cessation of the supervised program.

It is remarkable that even before the detraining period, those participants who had a fall already displayed lower values in all the HRQOL items, with differences being significant in physical role functioning, emotional role functioning and mental health compared to the non-fallers. Research about the relationship between the quality of life preceding a fall is scarce but interesting. It has been observed that the lowest quality of life scores was associated with a greater risk of falls [42]. Moreover, patients who suffered a wrist [43] and a hip [44] fracture following a fall, retrospectively recalled lower "pre-injury" values in various items of the SF-36, than non-fallers. Hence, the observed lower quality of life of fallers may be an interesting sign which may merit further research.

Moreover, participants who had a fall after the detraining period scored lower absolute HRQOL values and exhibited a larger decline than non-fallers in all dimensions, with differences in physical role functioning, general health and mental health items being statistically significant. The negative effect of a fall on the quality of life of the elderly has previously been demonstrated [10, 29]. Those people that suffered a fall probably had fear of falling again and it has an important impact on their quality of life [45].
Nevertheless, even after adjusting for the effect of fear of falling [29], the quality of life of fallers remained lower compared to non-fallers. A fall can imply an injury, limitations in physical activity, loss of independence and a decrease in psychological functioning [46], thus having a large impact on quality of life.

\section{Limitations}

The potential limitations of the present study should be taken into account. On the one hand, the study was undertaken in the absence of a control group, the inclusion of which would have allowed comparative data from a group of non-exercising elderly. On the other hand, the present study does not include a very large number of participants. However, it should be borne in mind that the recruitment of elderly people who had continuously been exercising for a long period of time (even years) in order to investigate the effect of detraining on habitual exercisers, is not an easy task. The interesting results obtained in the present study should encourage the design of larger research studies including different groups of participants and different variables.

\section{Conclusion}

There is an important decline in most items of the SF-36 following a 3 month detraining period. This decline is particularly evident in women and it is not related to a loss of handgrip strength. Therefore efforts should be made to either maintain the same type of exercise and/or shorten vacations or holiday break periods, particularly in the case of women. In addition, people who suffer a fall during the detraining period displayed lower HRQOL values not only after but also before the event, thus meriting further attention.

\section{Abbreviations \\ BMI: Body mass index; HRQOL: Health-related quality of life; WHO: World Health Organization}

\section{Acknowledgements \\ The authors would like to sincerely thank Getxo Kirolak for their collaboration in this study, as well as all the study participants for their commitment to facilitating the research. \\ Funding \\ Esain I was supported by a grant from the Basque Government (Pre_2014_1_137) This work was supported by the Basque Government (IT922-16). \\ Availability of data and materials \\ The datasets used and analyzed during the current study are available from the corresponding author on reasonable request.}

\section{Authors' contributions}

IE, IBL, ARL and SG were responsible for data collection. IE and SG analyzed and interpreted the data and were the major contributors to writing the

manuscript. All authors read and approved the final version of the manuscript.

Ethics approval and consent to participate

The study protocol was approved by the Ethics Committee of the University of the Basque Country (UPV/EHU) M10_2015-204. 


\section{Consent for publication}

Not applicable.

\section{Competing interests}

The authors declare that they have no competing interests.

\section{Publisher's Note}

Springer Nature remains neutral with regard to jurisdictional claims in published maps and institutional affiliations.

Received: 28 April 2017 Accepted: 14 November 2017 Published online: 21 November 2017

\section{References}

1. World Health Organization. 2017. http://www.who.int/en/. Accessed 14 Jan 2017.

2. Mora-Bautista G. El envejecimiento y la actividad fisica. Mov Cient. 2008;2:1

3. Giordano A, Pietro-Bonometti G, Vanoglio F, Paneroni M, Bernocchi P, Comini L, Giordano A. Feasibility and cost-effectiveness of a multidisciplinary home-telehealth intervention programme to reduce falls among elderly discharged from hospital: study protocol for a randomized controlled trial. BMC Geriatr. 2016;16:209.

4. Kwang-II K, Hye-Kyung J, Chang K, Soo-Kyung K, Hyun-Ho C, Dael K, Yong-Chan H, Sung-Hee H, Chang W, Jae-Young L, Hyun K, Jae K, The Korean association of Internal Medicine, The Korean Geriatrics Society. Evidence-based guidelines for fall prevention in Korea. Korean J Intern Med. 2017;32:199-210.

5. Buchner DM. Physical activity and prevention of cardiovascular disease in older adults. Clin Geriatr Med. 2009;25:661-75.

6. May AM, Struij EA, Frasen HP, Onland-Moret NC, de Wit GA, Boer JMA, van der Schouw YT, Hoekstra J, Bueno-de-Mesquita HB, Peeters PH, Beulens JW. The impact of a healthy lifestyle on disability-adjusted life years: a prospective cohort study. BMC Med. 2015;13:39.

7. Toraman NF, Eman A, Agyar E. Effects of multi-component training on functional fitness in older adults. J Aging Phys Act. 2004;26:448-54.

8. Pruitt LA, Taaffe DR, Marcus R. Effects of a one-year high-intensity versus low-intensity resistance training program on bone mineral density in older women. J Bone Miner Res. 1995:10(11):1788-95.

9. Tolomio S, Ermolao A, Travain G, Zaccaria M. Short-term adapted physical activity program improves bone quality in osteopenic/osteoporotic postmenopausal women. J Phys Act Health. 2008:5:844-53.

10. Sherrington C, Tiedemann A, Fairhall N, Close J, Lord S. Exercise to prevent falls in older adults: an updated meta-analysis and best practice recommendations. NWS Public Health Bulletin. 2011;22(3-4):78-83.

11. Cheung CL, Tan KCB, Bow CHB, Soong CSS, Loong CHN, Kung AW-H. Low handgrip strength is a predictor of osteoporotic fractures: cross-sectional and prospective evidence from the Hong Kong osteoporosis study. Age. 2012:34:1239-48.

12. Taekema DG, Gussekloo J, Maier AB, Westendorp RGJ, Craen AJM. Handgrip strength as a predictor of functional, psychological and social health. A prospective population-based study among the oldest old. Age Ageing. 2010:39:331-7.

13. Bohannon RW. Hand-grip dynamometry predicts future outcomes in aging adults. J Geriatr Phys Ther. 2008;31(1):3-10

14. World Health Organisation. WHOQOL-BREF introduction, administration, scoring and generic version of the assessment. Geneva: World Health Organisation; 1996.

15. López-García E, Banegas JR, Pérez-Regadera AG, Gutiérrez-Fisac UL, Alonso J, Rodríguez-Artalejo F. Valores de referencia de la versión española del Cuestionario de salud SF-36 en población adulta de más de 60 años. Med Clin (Barc). 2003;120(15):568-73.

16. Vilagut G, Ferrer M, Rajmil L, Rebollo P, Permanyer-Miralda G, Quitana JM, Santed R, Valderas JM, Ribera A, Domingo Salvany A, Alonso J. El cuestionario de Salud SF-36 español: una década de experiencia y nuevos desarrollos. Gac Sanit. 2005:19(2):135-50.

17. Hekmatpou D, Shamsi M, Zamani M. The effect of a healthy lifestyle program on the elderly's health in Arak. Indian J Med Sci. 2013:67(3-4):70-7.

18. Logsdon RG, McCurry SM, Pike KC, Teri L. Making physical activity accessible to older adults with memory loss: a feasibility study. Gerontologist. 2009; 49(Suppl 1):S94-9.
19. Walters SJ, Munro JF, Brazier JE. Using the SF.36 with older adults: a cross-sectional community based survey. Age Ageing. 2001;30(4):337-43.

20. Soto JR, Dopico X, Giraldez MA, Iglesias E, Amador F. La incidencia de programas de actividad física en la población de adultos mayores. Eur J Hum Mov. 2009;22:65-81.

21. Teixeira LE, Silva KN, Imoto AM, Kayo AH, Montenegro-Rodruigues $\mathrm{R}$, Peccin MS, Trevisiani VF. Progressive load training for the quadriceps muscle associated with proprioception exercises for the prevention of falls in postmenopausal women with osteoporosis: a randomized controlled trial. Osteoporos Int. 2010;21(4):589-96.

22. Küçükçakir N, Altan L, Korkmaz N. Effects of Pilates exercises on pain, functional status and quality of life in women with postmenopausal osteoporosis. J Body Mov Ther. 2013:17:204-11.

23. Hörder H, Skoog I, Frändin K. Health-related quality of life in relation to walking habits and fitness: a population-based study of 75-years-olds. Qual Life Res. 2013;22:1213-23.

24. Henwood TR, Taaffe DN. Detraining and retraining in older adults following long-term muscle power or muscle strength specific training. J Gerontol Med Sci. 2008:65(7):751-8.

25. Toraman NF, Ayceman N. Effects of six weeks of detraining on retention of functional fitness of old people after nine weeks of multicomponent training. Br J Sports Med. 2005;39:565-8.

26. Bocalini DS, Serra AJ, Rica RL, Dos Santos L. Repercussions of training and detraining by water-based exercise on functional fitness and quality of life: a short-term follow-up in healthy older women. Clinics. 2010;65(12):1305-9.

27. Texeira-Samela LF, Santiago L, Magalhâes RC, Murta D, Fernandez F, Gomes J. Functional performance and quality of life related to training and detraining of community-dwelling elderly. Disabil Rehabil. 2005;27(17):1007-12.

28. Lobo A, Carvalho J, Santos P. Effects of training and detraining on physical fitness, physical activity patterns, cardiovascular variables, and HRQoL after 3 health-promotion interventions in institutionalized elders. Int J Family Med. 2010;2010:486097.

29. Thiem U, KlaaBen-Mielke R, Trampisch U, Moschny A, Pientka L, Hinrichs T. Falls and EQ-5D rated quality of life in community-dwelling seniors with concurrent chronic diseases: a cross-sectional study. Health Qual Life Outcomes. 2014;12:2.

30. ISAK. International standards of anthropometric assessment. Australia: The international Society for advancement of Kinanthropometry; 2001.

31. Cruz-Jentoft AJ, Baeyens JP, Bauer JM, Boirie Y, Cederholm T, Landi F, Martin FC, Michel JP, Rolland Y, Schneider SM, Topinková E, Vandewoude M, Zamboni M. European working group on sarcopenia in older people. Sarcopenia: European consensus on definition and diagnosis: report of the European working group on sarcopenia in older people. Age Ageing. 2010; 39:412-23.

32. Sayer AA, Syddall HE, Martin HJ, Dennison EM, Anderson FH, Cooper C. Falls, sarcopenia and growth in early life: findings from the Hertfordshire cohort study. Am J Epidemiol. 2006:164(7):665-71.

33. Horowitz BP, Tollin R, Cassidy G. Grip strength: collection of normative data with community dwelling elders. Phys Occup Ther Geriatr. 1997;15(1):53-64

34. Encuesta de salud del País Vasco 2007. 2017. http://www.osakidetza.euskadi. eus/. Accessed 24 Jan 2017.

35. Cohen J. Statistical power analysis for the behavioral science. 2nd ed. Lawrence Earlbaum Associates: Hilldsdale; 1988.

36. Balboa-Castillo T, León-Muñoz LM, Graciani A, Rodríguez-Artalejo F, Guallar-Castillón P. Longitudinal association of physical activity and sedentary behavior during leisure time with health-related quality of life in community dwelling older adults. Health Qual Life Outcomes. 2011;9:47.

37. Ansai JH, Rebelatto JR. Effect of two physical exercise protocols on cognition and depressive symptoms in oldest-old people: a randomized controlled trial. Geriat Gerontol Int. 2015;15:1127-34.

38. Vuillemin A, Boini S, Bertrais S, Tessier S, Oppert JM, Hercberg S, Guillemin F, Briançon S. Leisure time physical activity and health-related quality of life. Pre Med. 2005:41:562-9.

39. Hermingway H, Stafford M, Stansfeld S, Shipley M, Marmot M. Is the SF-36 a valid measure of change in population health? Results from the Whitehall II study. BMJ. 1997;315:1273-9.

40. Zijlstra GA, Van Haasregt JC, Van Eijk JT, Van Rossunm E, Stalenhoef PA, Kempen GI. Prevalence and correlates of fear of falling, and associated avoidance of activity in the general population of community-living older people. Age Ageing. 2007;36(3):304-9. 
41. Toulotte C, Thevenon A, Fabre C. Effects of training and detraining on the static and dynamic balance in elderly fallers and non-fallers: a pilot study. Disabil Rehabil. 2006;28(2):125-33.

42. Bilotta C, Bowling A, Nicolini P, Casé A, Pina G, Rossi SV, Vergani C. Older People's quality of life(OPQOL) scores and adverse health outcomes at a one-year follow-up. A prospective cohort study on older outpatients living in the community in Italy. Health Qual Life Outcomes. 2011;9:72.

43. Rohde G, Mengshoel AM, Wahl AK, Moum T, Haugeberg G. Is health-related quality of life associated with the risk of low-energy wrist fracture: a casecontrol study. BMC Musculoskelet Disord. 2009;10:80.

44. Rohde G, Mengshoel AM, Haugeberg G, Moum T, Wahl AK. Is global quality of life reduced before fracture in patients with low-energy wrist or hip fracture? A comparison with matched controls. Health Qual Life Outcomes. 2008;6:90.

45. Asai T, Misu S, Sawa R, Doi T, Yamada M. The association between fear of falling and smoothness of lower trunk oscillation in gait varies according to gait speed in community-dwelling older adults. J Neuroeng Rehabil. 2017;14:5.

46. Tsonga T, Michalopoulou M, Kapetanakis S, Giovannopoulou E, Malliou P, Godolias G, Soucacos P. Risk factors for fear falling in elderly patients with severe knee osteoarthritis before and one year after total knee arthroplasty. J Orthop Surg Res. 2016;24(3):302-6.

\section{Submit your next manuscript to BioMed Central} and we will help you at every step:

- We accept pre-submission inquiries

- Our selector tool helps you to find the most relevant journal

- We provide round the clock customer support

- Convenient online submission

- Thorough peer review

- Inclusion in PubMed and all major indexing services

- Maximum visibility for your research

Submit your manuscript at www.biomedcentral.com/submit 